\title{
Bilirubin Diglucuronide Formation in Intact Rats
}

\section{and in Isolated Gunn Rat Liver}

\author{
J. Roy Chowdhury, N. Roy Chowdhury, Ulrich GärtNer, \\ Allan W. Wolkoff, and Irwin M. ARIAS, The Liver Research Center, \\ Albert Einstein College of Medicine, Bronx, New York 10461
}

A B S T R A C T Bilirubin diglucuronide (BDG) may be formed in vitro by microsomal UDP glucuronosyl transferase (EC 2.4.1.17)-mediated transfer of a second mole of glucuronic acid from UDP-glucuronic acid, or by dismutation of bilirubin monoglucuronide (BMG) to BDG and unconjugated bilirubin, catalyzed by an enzyme (EC 2.4.1.95) that is concentrated in plasma membrane-enriched fractions of rat liver. To evaluate the role of these two enzymatic mechanisms in vivo, $\left[{ }^{3} \mathrm{H}\right]$ bilirubin mono- $\left[{ }^{14} \mathrm{C}\right]$ glucuronide was biosynthesized, purified by thin-layer chromatography, and tracer doses were infused intravenously in homozygous Gunn (UDP glucuronyl transferase-deficient) rats or Wistar rats. Bilirubin conjugates in bile were separated by high-pressure liquid chromatography and ${ }^{3} \mathrm{H}$ and ${ }^{14} \mathrm{C}$ were quantitated. In Gunn rats, the ${ }^{14} \mathrm{C}:{ }^{3} \mathrm{H}$ ratio in $\mathrm{BDG}$ excreted in bile was twice the ratio in injected $\mathrm{BMG}$. In Wistar rats the ${ }^{14} \mathrm{C}:{ }^{3} \mathrm{H}$ ratio in biliary BDG was $1.25 \pm 0.06$ (mean \pm SEM)times the ratio in injected BMG. When double labeled BMG was injected in Wistar rats after injection of excess unlabeled unconjugated bilirubin $(1.7 \mu \mathrm{mol})$, the ${ }^{14} \mathrm{C}:{ }^{3} \mathrm{H}$ ratio in BDG excreted in bile was identical to the ratio in injected BMG. Analysis of isomeric composition of bilirubin conjugates after alkaline hydrolysis or alkaline methanolysis indicated that the bile pigments retained the $\mathrm{IX}_{\alpha}$ configuration during these experiments. The results indicate that both enzymatic dismutation and UDP glucuronyl transferase function in vivo in BDG formation, and that dismutation is inhibited by a high intrahepatic concentration of unconjugated bilirubin. This hypothesis was supported by infusion of $\left[{ }^{3} \mathrm{H}\right]$ bilirubin-monoglucuronide in isolated perfused homozygous Gunn rat liver after depletion of intrahepatic bilirubin by perfusion with bovine serum albumin $(2.5 \%)$, and after bilirubin repletion following perfusion with $0.34 \mathrm{mM}$ bilirubin. From 20 to $25 \%$ of

Address reprint requests to Dr. J. Roy Chowdhury.

Received for publication 27 February 1981 and in revised form 14 September 1981 . injected radioactivity was recovered in BDG in bile in the bilirubin-depleted state; only $8-10 \%$ of radioactivity was in BDG in bile after bilirubin repletion.

After infusion of $\left[{ }^{3} \mathrm{H}\right]$ bilirubin $\mathrm{di}-\left[{ }^{14} \mathrm{C}\right]$ glucuronide in homozygous Gunn rats, $5-7 \%$ of the injected pigment was excreted in bile as BMG. The ${ }^{14} \mathrm{C}:{ }^{3} \mathrm{H}$ ratio in the injected BDG was $10 \%$ greater than the ${ }^{14} \mathrm{C}:{ }^{3} \mathrm{H}$ ratio in BMG excreted in bile. These results indicate that in vivo, dismutation rather than partial hydrolysis, is responsible for BMG formation.

Incubation of $\left[{ }^{3} \mathrm{H}\right]$ bilirubin, BDG and a rat liver plasma membrane preparation resulted in formation of BMG $(3.3 \mathrm{nmol} / \mathrm{min}$ per $\mathrm{mg}$ protein) indicating that dismutation is also reversible in vitro.

\section{INTRODUCTION}

Bilirubin diglucuronide (BDG) ${ }^{1}$ is the major bilirubin conjugate in human, rat, and dog bile (1-3). Uridine diphosphoglucuronate glucuronosyl transferase (UDP glucuronyl transferase, UDPGT, EC 2.4.1.17) activity is concentrated in liver microsomes, and catalyzes the transfer of a glucuronyl moiety from UDP glucuronate to bilirubin. The predominant reaction product in vitro is bilirubin monoglucuronide (BMG) (4-6). A second enzyme, which is concentrated in plasma membraneenriched fractions of rat liver homogenates, has been provisionally termed bilirubin glucuronoside glucuronosyl transferase (EC 2.4.1.95), and dismutates 2 mol of BMG to $1 \mathrm{~mol}$ of BDG and $1 \mathrm{~mol}$ of unconjugated bilirubin (6). Dismutating enzyme activity is normal in liver from UDP glucuronyl transferase-deficient man (Crigler-Najjar syndrome Type I) and rat (Gunn strain) (7). The enzyme was purified from a plasma membrane-enriched fraction of rat liver ho-

\footnotetext{
${ }^{1}$ Abbreviations used in this paper: BDG, bilirubin diglucuronide; BMG, bilirubin monoglucuronide; HPLC, highpressure liquid chromatography; tlc, thin-layer chromatography; UDPGT, uridine diphosphoglucuronate glucuronosyl transferase.
} 
mogenate (8). The mechanism of dismutation is uncertain and may involve transfer of a glucuronosyl moiety from one BMG molecule to another, or enzyme-catalyzed dipyrrole rearrangement forming bilirubin $\mathrm{IX}_{\alpha}$ diglucuronide and unconjugated bilirubin IX

Cat (9) and rat (10) liver microsomes catalyze UDP glucuronic acid-dependent BDG formation in vitro. Thus, BDG formation may result from both UDPGT activity and dismutation of BMG in vitro.

The relative role of UDP glucuronyl transferase and dismutation of BMG in BDG formation in vivo is uncertain. The present study was undertaken to examine the function of these two enzymes in BDG formation in intact rats and in isolated perfused Gunn rat liver.

\section{METHODS}

\section{Experimental procedure}

\section{Materials}

Male Wistar rats (200-250 g) were from Marland Farms, Peekskill, N. Y. Male Gunn rats were the gift of Dr. Carl Hansen, National Institutes of Health, Bethesda, Md.

Bilirubin and uridine diphosphoglucuronic acid, ammonium salt were from Sigma Chemical Co., St. Louis, Mo. High-pressure liquid chromatography (HPLC) grade chloroform, methanol, acetonitrile and water and 1-heptane sulfonic acid were obtained from Waters Associates, Milford, Mass. Ethyl anthranilate was from Eastman Kodak Co., Rochester, N. Y., glucaro-1,4-lactone from CalbiochemBehring Corp., San Diego, Calif., and Triton X-100 from New England Nuclear, Boston, Mass. Uridine diphosphoglucuronic acid with the glucuronyl moiety labeled uniformly with ${ }^{14} \mathrm{C}(290 \mathrm{mCi} / \mathrm{mmol})$, ammonium salt was obtained from Amersham/Searle Corp., Arlington Heights, Ill. Delta amino levulinic acid-2,3- ${ }^{3} \mathrm{H}($ sp act $7 \mathrm{mCi} / \mathrm{mmol}$ ) was from Schwarz/Mann, Div. Becton, Dickinson \& Co., Orangeburg, N. Y. The radiochemicals were used without further purification. For thin-layer chromatography (tlc), glass plates precoated with silica gel (Silicagel G-60, $0.25 \mathrm{~mm}, 20$ $\times 20 \mathrm{~cm}$ ) were used (E. Merck, Darmstadt, West Germany).

HPLC was performed with a Waters Associates liquid chromatograph consisting of two pumps, solvent programmer, ultra-violet/visible detection system and programmable automatic injector (WISP). The chromatogram was recorded with a Houston two-pen recorder (Houston Instrument Div., Bausch \& Lomb, Inc., Austin, Tex.), and the area under the peaks was integrated with an electronic integrator (Autolab-I Spectraphysics, Santa Clara, Calif.). A $10-\mu \mathrm{m}$ pore size C-18 column (Waters Associates " $\mu$-Bondapak C-18") was used.

\section{General METHODS}

Preparation of $\left[{ }^{3} \mathrm{H}\right]$ bilirubin. Delta-amino levulinic acid$2,3-{ }^{3} \mathrm{H}, 175 \mathrm{nmol}(25 \mathrm{mCi})$ was injected intravenously into a dog that had a bile fistula (11). Bile was collected in 4-h fractions with ascorbic acid as preservative. Conjugated bile pigments were subjected to alkaline hydrolysis; bilirubin was extracted and crystallized to constant specific activity (12), and bilirubin $\mathrm{IX}_{\alpha}$ was purified by tlc (13).
Preparation of $\left[{ }^{3} \mathrm{H}\right]$ bilirubin mono- $\left[{ }^{14} \mathrm{C}\right]$ glucuronide and $\left[{ }^{3} \mathrm{H}\right]$ bilirubin monoglucuronide. BMG was prepared biosynthetically (6). UDP-glucuronyl transferase activity of rat liver microsomes was activated by incubation with Triton $\mathrm{X}-100(0.25 \%, \mathrm{vol} / \mathrm{vol})$ at $4^{\circ} \mathrm{C}$ for $10 \mathrm{~min}$. Activated microsomes were incubated with $\mathrm{MgCl}_{2}(3.3 \mathrm{mM})$, UDP glucuronic acid $(2.6 \mathrm{mM})$, and bilirubin $(0.083 \mathrm{mM})$ in Tris/HCl buffer $\left(0.1 \mathrm{M}, \mathrm{pH} 8.0\right.$, at $\left.37^{\circ} \mathrm{C}\right)$ in a dark nitrogen atmosphere at $37^{\circ} \mathrm{C}$ for $15 \mathrm{~min}$. For synthesis of $\left[{ }^{3} \mathrm{H}\right]$ bilirubin monoglucuronide, the incubation mixture contained $\left[{ }^{3} \mathrm{H}\right]$ bilirubin $(2-$ $5 \mu \mathrm{Ci})$. The incubation mixture for synthesis of $\left[{ }^{3} \mathrm{H}\right]$ bilirubin mono- $\left[{ }^{14} \mathrm{C}\right]$ glucuronide also contained UDP- $\left[{ }^{14} \mathrm{C}\right] \mathrm{glucuronic}$ acid, ammonium salt $(5 \mu \mathrm{Ci})$. After incubation, the mixture was stirred with $0.2 \%$ lauryl sodium sulfate (wt/vol) at $4^{\circ} \mathrm{C}$; pH was lowered to 3.2 by addition of $10 \mathrm{M} \mathrm{HCl}$, and pigments were extracted into ethyl acetate in a nitrogen atmosphere. The organic solvent was separated by centrifugation and evaporated in reduced pressure. Bile pigments were dissolved in $2 \mathrm{ml}$ ethylacetate and applied as streaks on tlc plates (glass precoated with $0.25 \mathrm{~mm}$ thick silica gel, "Silicagel G-60," E. Merck) that were developed in chloroform/methanol/water (65:35:8, vol/vol/vol) (14) in a dark nitrogen atmosphere. Previously purified BMG was used as reference. The band containing BMG was removed by scraping; pigment was extracted in $2 \mathrm{ml}$ methanol, and silica gel was removed by centrifugation. Glycine/ $\mathrm{HCl}$ buffer, $0.1 \mathrm{M}$, $\mathrm{pH} 2.7$, containing $2 \%$ ascorbic acid (wt/vol), $4 \mathrm{ml}$ was added, and the mixture was filtered through a $0.45-\mu \mathrm{m}$ filter (Millipore Corp., Bedford, Mass., FH) to remove precipitated particles. The filtrate was shaken with chloroform, 4 $\mathrm{ml}$ at room temperature in a nitrogen atmosphere. The chloroform extract was separated by centrifugation $(15,000 \mathrm{~g} \times 1$ $\mathrm{min}$ ) and washed with glycine/ $\mathrm{HCl}$ buffer. The organic solvent was evaporated in reduced pressure in a centrifugal evaporator ("Speedvac", Savant Instruments, Inc., Hicksville, N. Y.) equipped with a glass organic solvent trap immersed in liquid nitrogen. Pure bilirubin monoglucuronide was stored in nitrogen at $-170^{\circ} \mathrm{C}$.

Preparation of $\left[{ }^{3} \mathrm{H}\right]$ bilirubin di- $\left[{ }^{14} \mathrm{C}\right]$ glucuronide or BDG. The incubation mixture was the same as that used for preparation of BMG. After extraction in ethyl acetate, the organic solvent was evaporated in reduced pressure. Bile pigments were dissolved/suspended in Tris/ $\mathrm{HCl}$ buffer, $0.1 \mathrm{M}$, pH $8.0,2 \mathrm{ml}$. Rat liver plasma membrane (15), $2 \mathrm{ml}(6 \mathrm{mg}$ protein) was incubated at $25^{\circ} \mathrm{C}$ with sodium phosphate buffer (0.1 M, pH 6.4) $4 \mathrm{ml}$ and glucaro-1,4-lactone $(5 \mathrm{mM})$ at $37^{\circ} \mathrm{C}$ for $3 \mathrm{~min}(6)$, when the reaction was stopped by addition of glycine/ $\mathrm{HCl}$ buffer, $0.4 \mathrm{M}, \mathrm{pH} 1.8$, saturated with $\mathrm{NaCl}$ containing $2 \%$ ascorbic acid. Bile pigments were extracted by vigorous shaking with an equal volume of chloroform/ethanol $(1: 1, \mathrm{vol} / \mathrm{vol})$. The organic solvents were separated by centrifugation $(15,000 \mathrm{~g} \times 1 \mathrm{~min})$, concentrated in reduced pressure, and applied as streaks on silica gel tlc plates. Previously purified BDG (14) was used as reference. After development in chloroform/methanol/water $(65: 35: 8$, $\mathrm{vol} / \mathrm{vol} / \mathrm{vol}$ ) in a nitrogen atmosphere, the band containing BDG was removed by scraping, pigment was extracted in methanol, and the solvent was removed in reduced pressure. The pigment was stored in nitrogen at $-170^{\circ} \mathrm{C}$. For preparation of $\left[{ }^{3} \mathrm{H}\right]$ bilirubin $\left[{ }^{14} \mathrm{C}\right]$ diglucuronide, labeled substrates were used in the initial incubation mixture as described for preparation of radiolabeled BMG.

Separation of BMG and BDG from bile by tlc and HPLC. (a) (tlc): Bile samples were mixed with 4 vol of glycine/HCl buffer, $0.4 \mathrm{M}, \mathrm{pH} 1.8$, saturated with sodium chloride and 5 vol of chloroform/ethanol (1:1, vol/vol). A pinch of ascorbic acid was added and bile pigments were 
extracted into the organic solvents by vigorous shaking (16). The organic phase was separated by centrifugation, reduced in volume in reduced pressure and applied to tlc plates (silicagel, $0.25 \mathrm{~mm}$ thick). Previously purified BMG and BDG were used as reference. Appropriate bands were scraped into centrifuge tubes; pigments were extracted in methanol, and silica gel was removed by centrifugation. (b) HPLC: Bile was mixed with an equal volume of methanol and centrifuged at $15,000 \mathrm{~g} \times 3 \mathrm{~min}$. The supernate $(0.005$ to $0.2 \mathrm{ml})$ was injected in a Waters' high pressure liquid chromatograph. The column was equilibrated with $50 \%$ methanol in sodium acetate buffer, $0.1 \mathrm{M}, \mathrm{pH} 4.0$, containing 1-heptane sulfonic acid, $5 \mathrm{mM}$. The column was eluted with a concave gradient of methanol $(50-100 \%$ in $60 \mathrm{~min}$ at a flow rate of $1 \mathrm{ml} / \mathrm{min}$ ) in the above buffer. Elution was continued for $70 \mathrm{~min}$. Absorption of eluate fractions at $436 \mathrm{~nm}$ was determined, and peak areas were electronically integrated.

Identification of peaks: (a) Peaks were identified from comigration of biosynthesized BMG and BDG, which were purified by tlc. (b) Pigment peaks were mixed with an equal volume of ethyl anthranilate diazo reagent (17). After 30 min at $25^{\circ} \mathrm{C}$, methanol was evaporated in reduced pressure, and azodipyrroles were extracted in $1 \mathrm{ml}$ methyl propyl ketone/butyl acetate $(17: 3, \mathrm{vol} / \mathrm{vol})$ and quantitated after separation by tlc (17).

Quantitation of BMG and BDG from chromatographic peaks: $\left[{ }^{3} \mathrm{H}\right]$ bilirubin mono- and diglucuronide were biosynthesized and purified as described. From $50 \mathrm{pmol}$ to $40 \mathrm{nmol}$ of labeled pigments were injected three consecutive times in the HPLC. Peaks $(436 \mathrm{~nm})$ were collected and pigments were quantitated from ${ }^{3} \mathrm{H}$ counts. The peak area per nanomole was determined.

Stability of bile pigments during HPLC and storage of bile: $\left[{ }^{3} \mathrm{H}\right]$ bilirubin monoglucuronide and $\left[{ }^{3} \mathrm{H}\right]$ bilirubin $\mathrm{di}-$ glucuronide were separated by HPLC and isolated pigments were collected and rechromatographed. The single peaks were collected and ${ }^{3} \mathrm{H}$ was counted. $\left[{ }^{3} \mathrm{H}\right]$ bilirubin monoglucuronide and $\left[{ }^{3} \mathrm{H}\right]$ bilirubin diglucuronide that had been isolated by HPLC were also mixed with rat bile and stored at $-170^{\circ} \mathrm{C}$ for $1 \mathrm{wk}$. Stored bile samples were chromatographed and radioactivity of isolated BMG and BDG was counted.

Reproducibility of HPLC analysis: Normal rat bile, $0.5 \mathrm{ml}$ was mixed with methanol, $0.5 \mathrm{ml}$ and centrifuged $(15,000$ $g \times 3 \mathrm{~min})$. Samples from the supernatant $(0.005,0.025$, $0.075,0.1$, and $0.15 \mathrm{ml}$ ) were chromatographed and BMG and BDG were quantitated from peak areas. A sample $(0.05$ $\mathrm{ml}$ ) was injected five consecutive times and BMG and BDG were quantitated. Between injections, bile samples were stored at $-70^{\circ} \mathrm{C}$ in the dark.

Radioactivity of the isolated pigment peaks: To decrease quenching and increased accuracy of counting, isolated bile pigments that were eluted from the HPLC column were exposed overnight to long wavelength ultraviolet light in sealed glass vials. This procedure bleached bile pigments and markedly decreased quenching. Aquasol (New England Nuclear), $15 \mathrm{ml}$, was added and ${ }^{3} \mathrm{H}$ and ${ }^{14} \mathrm{C}$ were counted to $1 \%$ error, three times after storage in the dark for $16 \mathrm{~h}$. Quenching for ${ }^{3} \mathrm{H}$ and ${ }^{14} \mathrm{C}$ in each sample, cross-over of ${ }^{3} \mathrm{H}$ counts into the ${ }^{14} \mathrm{C}$ channel and cross-over of ${ }^{14} \mathrm{C}$ counts into the ${ }^{3} \mathrm{H}$ channel were calculated using internal standards. Standard deviation of ${ }^{14} \mathrm{C} /{ }^{3} \mathrm{H}$ ratios ranged from 0.5 to $1.8 \%$ of means.

\section{SPECIFIC METHODS}

Experiments in rats in vivo. Intravenous infusion of $\left[{ }^{3} \mathrm{H}\right]$ bilirubin mono- $\left[{ }^{14} \mathrm{C}\right]$ glucuronide in homozygous Gunn or
Wistar rats: Under light ether anesthesia, rats were provided with polyethylene cannulae (PE 10, Intramedic, Clay Adams, Inc., New York) in the jugular vein and bile duct. $1 \mathrm{~h}$ later, the rats regained consciousness, and two bile samples (30 min each) were collected. Only animals producing $0.3 \mathrm{ml}$ or more bile per $30 \mathrm{~min}$ were used. Pure $\left[{ }^{3} \mathrm{H}\right]$ bilirubin mono$\left[{ }^{14} \mathrm{C}\right]$ glucuronide, $20-40 \mathrm{nmol}$ dissolved by vigorous shaking in nitrogen atmosphere in $1 \mathrm{ml}$ rat serum was infused intravenously. Bile was collected for $30 \mathrm{~min}$ on ice in the dark in tubes containing $0.1 \mathrm{ml} 10 \%$ ascorbic acid solution. BMG and BDG were separated by tlc or HPLC, and ${ }^{3} \mathrm{H}$ and ${ }^{14} \mathrm{C}$ radioactivities were determined. In two Wistar rats, $\left[{ }^{3} \mathrm{H}\right]$ bilirubin mono- $\left[{ }^{14} \mathrm{Clglucuronide}\right.$ was infused before and $2 \mathrm{~h}$ after infusion of $1.7 \mu \mathrm{mol}$ unconjugated bilirubin $(1.7$ $\mu \mathrm{mol}$ bilirubin dissolved in $0.1 \mathrm{ml} \mathrm{NaOH}, 0.05 \mathrm{M}$, and diluted to $1 \mathrm{ml}$ with rat serum). Bile was collected and pigments were analyzed by HPLC as described.

In each experiment, the last $0.1 \mathrm{ml}$ of infusate was saved for analysis by HPLC and determination of radioactivity. In two experiments, $0.1 \mathrm{ml}$ of infusate was also mixed with $1 \mathrm{ml}$ of Gunn rat bile and stored on ice for $2 \mathrm{~h}$ to evaluate degradation and dipyrrolic scrambling (18) of bile pigments during storage. Bile and infusate samples were stored in the dark in nitrogen at $-70^{\circ} \mathrm{C}$, and were analyzed within $6 \mathrm{~h}$.

To evaluate the role of dipyrrolic scrambling (18) in the formation of BDG, $0.1 \mathrm{ml}$ of perfusate and $0.1 \mathrm{ml}$ of the bile after BMG infusion from two Wistar rat experiments were hydrolyzed in $\mathrm{NaOH}(1 \mathrm{M})$ that contained $0.4 \%$ ascorbic acid (18). Unconjugated bilirubin was extracted in chloroform after acidification and mixed with bilirubin (Sigma Chemical Co.) in chloroform solution. Bilirubin isomers were separated by tlc (13); III ${ }_{\alpha}, I_{\alpha}$, and $\mathrm{XIII}_{\alpha}$ bands were scraped, and radioactivity was determined. The isomeric configuration of bile pigments was further examined in the following experiments. Purified $\left[{ }^{3} \mathrm{H}\right]$ bilirubin monoglucuronide, 50-98 $\mathrm{nmol}$, was dissolved in $0.1 \mathrm{M}$ sodium phosphate buffer, $\mathrm{pH} 7.8$, containing $4 \mathrm{mM}$ sodium ascorbate, and $0.9 \mathrm{ml}$ was injected within $2 \mathrm{~min}$ in two Gunn rats and one Wistar rat. Bile pigments in the last $0.1 \mathrm{ml}$ of the infusate and in bile collected for $45 \mathrm{~min}$ after the infusion were analyzed by tlc after alkaline methanolysis as described by Blanckaert (19). Bands representing bilirubin dimethylester and the four isomers of monomethylester $\left(\mathrm{III}_{\alpha}, \mathrm{XIII}_{\alpha}, \mathrm{IX}_{\alpha}, \mathrm{C}-8\right.$, and C-12) were removed by scraping; radioactivity was determined after quench correction using an internal standard. To obtain reference methylesters, bilirubin $\mathrm{III}_{\alpha}, \mathrm{XIII}_{\alpha}$ and $\mathrm{IX}_{\alpha}$ were produced by acid-catalyzed dipyrrolic disproportionation of commercial bilirubin (Sigma Chemical Co.) (20). A mixture of the three isomers of bilirubin $(2 \mathrm{mg}$ ) was dissolved in 0.25 $\mathrm{ml}$ of $0.01 \mathrm{~N} \mathrm{NaOH}$, diluted to $2 \mathrm{ml}$ with sodium phosphate, $0.1 \mathrm{M}$, pH 7.8, and injected intravenously in a Wistar rat that was provided with a bile duct cannula. Bile was collected for $2 \mathrm{~h}$, bilirubin conjugates were converted to methylesters by akaline methanolysis, and the dimethylester and monomethylester isomers were separated by tlc as described by Blanckaert (19).

Infusion of ${ }^{3} \mathrm{H}$-bilirubin $\mathrm{di}^{14} \mathrm{C}$-glucuronide in homozygous Gunn rats: Homozygous Gunn rats were prepared as described and infused with $20 \mathrm{nmol}$ of double-labeled BDG dissolved by vigorous shaking in nitrogen atmosphere in 1 $\mathrm{ml}$ rat serum. Bile was collected for $30 \mathrm{~min}$, pure unlabeled BMG, $20 \mathrm{nmol}$, was added as reference pigment, BMG and BDG were separated by HPLC, and ${ }^{3} \mathrm{H}$ and ${ }^{14} \mathrm{C}$ were counted.

Experiments in isolated perfused homozygous Gunn rat liver. The portal vein, vena cava, and bile duct were cannulated and the liver was perfused in situ with Krebs-Hen- 
seleit solution containing $2.5 \%$ bovine serum albumin (fraction V) and bovine erythrocytes (hematocrit 20\%) in a recirculating system. Temperature was maintained at $37^{\circ} \mathrm{C}$. $\mathrm{PO}_{2}$ and $\mathrm{PCO}_{2}$ were maintained at 100 and $40 \mathrm{~mm} / \mathrm{Hg}$ by bubbling a mixture of oxygen (95\%) and $\mathrm{CO}_{2}(5 \%)$. Only livers producing $0.015 \mathrm{ml}$ bile/min were used.

Determination of bilirubin concentration in liver homogenates before and after perfusion: Gunn rat liver was per-

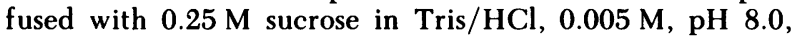
minced and homogenized with $3 \mathrm{ml} / \mathrm{g}$ liver of the same buffer. Isolated liver from Gunn rats was perfused with buffer containing $2 \%$ bovine serum albumin and homogenized as described. Liver homogenates $(0.2 \mathrm{ml})$ were diazotized with $p$-iodoaniline diazo reagent (21): azoproducts were extracted in butyl acetate, and total bilirubin was determined.

Infusion of $\left[{ }^{3} \mathrm{H}\right]$ bilirubin monoglucuronide: After perfusion of isolated Gunn rat liver with albumin-containing Krebs-Henseleit solution for $30 \mathrm{~min}, 37-40 \mathrm{nmol}\left[{ }^{3} \mathrm{H}\right] \mathrm{bilirubin}$ monoglucuronide was dissolved in $1 \mathrm{ml}$ rat serum and injected into the portal vein. The last $0.1 \mathrm{ml}$ in the syringe was analyzed by HPLC. Bile was collected for $30 \mathrm{~min}$ in the dark, bile pigments were separated by tlc, and radioactivity of BMG and BDG was determined. Unconjugated bilirubin (40 mg dissolved in $4 \mathrm{ml}$ of $0.05 \mathrm{~N} \mathrm{NaOH}$, diluted five times with rat serum) was added to the perfusion fluid reservoir to a concentration of $0.34 \mathrm{mM}$. After $30 \mathrm{~min}$ of perfusion with the bilirubin-containing perfusate, $\left[{ }^{3} \mathrm{H}\right]$ bilirubin monoglucuronide was injected, bile was collected, and pigments were analyzed. In two other Gunn rats, isolated liver was initially perfused with bilirubin-containing perfusate, $\left[{ }^{3} \mathrm{H}\right]$ bilirubin monoglucuronide was then injected, and bile was collected for $30 \mathrm{~min}$ when the perfusion was changed to a nonbilirubin-containing solution and $\left[{ }^{3} \mathrm{H}\right]$ bilirubin monoglucuronide was reinjected $30 \mathrm{~min}$ later.

Conversion of BDG and unconjugated bilirubin to BMG. BDG, $4 \mu \mathrm{M}$, unconjugated $\left[{ }^{3} \mathrm{H}\right]$ bilirubin $10 \mu \mathrm{M}(0.5 \mu \mathrm{Ci} /$ incubation mixture) and a rat liver plasma membrane preparation (Fraction $\mathrm{N}_{2}$ of Touster et al. [15], $20 \mu \mathrm{g}$ protein) (14) were incubated in a final volume of $0.2 \mathrm{ml}, \mathrm{pH} 6.6$, in $0.05 \mathrm{M}$ sodium phosphate buffer containing $0.25 \%$ Triton $\mathrm{X}$ 100 for varying time periods at $37^{\circ} \mathrm{C}$. The reaction was stopped by transferring the tubes to ice and addition of glycine/ $\mathrm{HCl}$ buffer, $0.4 \mathrm{M}, \mathrm{pH} 1.8$, saturated with sodium chloride $2 \mathrm{ml}$ and a pinch of ascorbic acid. The mixture was shaken vigorously under nitrogen at room temperature in the dark with chloroform/ethanol $(1: 1, \mathrm{vol} / \mathrm{vol}), 3 \mathrm{ml}$. The chloroform/ethanol extract containing the bile pigments was separated by centrifugation, and evaporated under reduced pressure in a centrifugal evaporator (Speedvac, Savant Corp.). The residue was dissolved in $0.075 \mathrm{ml}$ dimethyl sulfoxide and $0.075 \mathrm{ml}$ of water, and centrifuged $(15,000 \mathrm{~g}$ $\times 3 \mathrm{~min}$ ), and the supernatant containing $97-99 \%$ radioactivity was analyzed by HPLC. BMG formation was quantitated from radioactivity of isolated BMG.

\section{RESULTS}

HPLC of normal Wistar rat bile revealed two major peaks (Fig. 1). The pigment that comigrated with biosynthesized BMG yielded equal amounts of unconjugated $(\alpha)$ and glucuronidated $(\delta)$ azodipyrroles on diazotization with diazo reagent (17). The other major peak, which comigrated with BDG yielded only glucuronidated azodipyrrole.
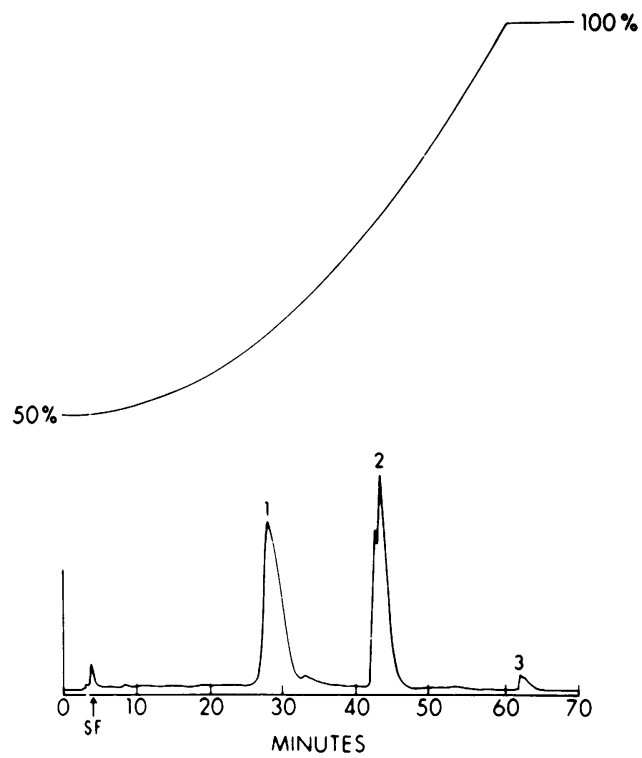

Figure 1 Representative HPLC of normal rat bile. Rat bile was mixed with an equal volume of methanol and centrifuged at $15,000 \mathrm{~g}$ for $1 \mathrm{~min}$, and $0.05 \mathrm{ml}$ of the supernate was analyzed by HPLC (see text). Peaks 1,2 , and 3 were identified as BDG, BMG, and unconjugated bilirubin, respectively.

Reproducibility of HPLC analysis. Areas under chromatographic peaks were linear with amounts of $\left[{ }^{3} \mathrm{H}\right]$ bilirubin monoglucuronide or $\left[{ }^{3} \mathrm{H}\right]$ bilirubin diglucuronide from 50 to $40 \mathrm{nmol}$. On three consecutive analyses standard deviations for each point were 0.4$1.6 \%$ of the mean.

Stability of pigments during storage and chromatography. When $\left[{ }^{3} \mathrm{H}\right]$ bilirubin mono- and diglucuronides that had been isolated by HPLC were rechromatographed, single peaks containing $97-99 \%$ of radioactivity were observed. When pure $\left[{ }^{3} \mathrm{H}\right]$ bilirubin mono- or diglucuronides that had been stored in Gunn rat bile at $-170^{\circ} \mathrm{C}$, were chromatographed, 94-98\% radioactivity was recovered in the appropriate peaks. There was no spontaneous conversion of BMG or BDG or vice versa. The results indicate that bilirubin glucuronides are stable during HPLC and storage under the conditions used in this study.

Infusion of $\left[{ }^{3} \mathrm{H}\right]$ bilirubin mono- $\left[{ }^{14} \mathrm{C}\right]$ glucuronide in Gunn rats. An aliquot of injected $\left[{ }^{3} \mathrm{H}\right]$ bilirubin mono$\left[{ }^{14} \mathrm{C}\right]$ glucuronide was $99 \%$ pure when analyzed by HPLC and contained no BDG. There was no spontaneous conversion of BMG to BDG after storage on ice for $2 \mathrm{~h}$ in Gunn rat bile. Fig. 2 shows a HPLC tracing of Gunn rat bile before and after BMG infusion. The control bile lacks bilirubin glucuronide. After BMG infusion, BMG and BDG were present in bile. From 66 to $75 \%$ of injected ${ }^{3} \mathrm{H}$ radioactivity and from 73 to 

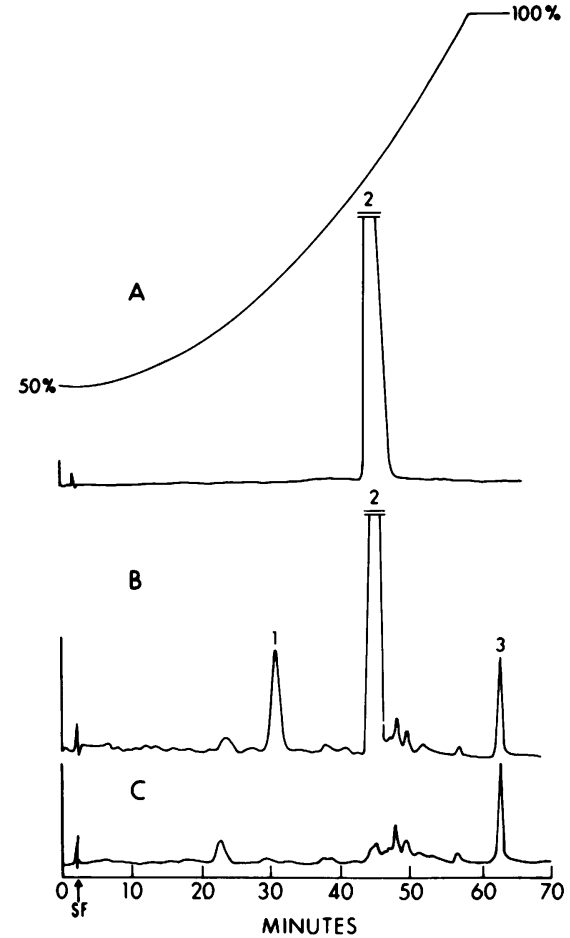

Figure 2 HPLC of purified $\left[{ }^{3} \mathrm{H}\right]$ bilirubin mono- $\left[{ }^{14} \mathrm{C}\right]$ glucuronide (A), control Gunn rat bile $(C)$ and Gunn rat bile after infusion of $\left[{ }^{3} \mathrm{H}\right]$ bilirubin mono- $\left[{ }^{14} \mathrm{C}\right]$ glucuronide (B). $\left[{ }^{3} \mathrm{H}\right]$ bilirubin mono- $\left[{ }^{14} \mathrm{C}\right]$ glucuronide was biosynthesized and purified as described in text. Chromatographic method was as in Fig. 1. (See legend of Fig. 1.)

$90 \%$ of injected ${ }^{14} \mathrm{C}$ radioactivity were recovered in bile in 30 min. From 8 to $10 \%$ of injected ${ }^{3} \mathrm{H}$ counts were in BDG. The ${ }^{14} \mathrm{C}:{ }^{3} \mathrm{H}$ ratio in injected $\mathrm{BMG}$ was equal to the ${ }^{14} \mathrm{C}:{ }^{3} \mathrm{H}$ ratio in $\mathrm{BMG}$ excreted in bile, and was half the ${ }^{14} \mathrm{C}:{ }^{3} \mathrm{H}$ ratio in $\mathrm{BDG}$ excreted in bile (Table I). These results indicate that the second mole of glucuronic acid in BDG excreted in bile is derived from the injected double-labeled BMG.

Infusion of $\left[{ }^{3} \mathrm{H}\right]$ bilirubin mono- $\left[{ }^{14} \mathrm{C}\right.$ glucuronide in Wistar rats (Table I). From 80 to $90 \%$ of injected ${ }^{3} \mathrm{H}$ radioactivity and 80 to $84 \%$ of injected ${ }^{14} \mathrm{C}$ radioactivity were recovered in bile in $30 \mathrm{~min}$. From 27 to $30 \%$ of injected ${ }^{3} \mathrm{H}$ radioactivity was in BDG. The ${ }^{14} \mathrm{C}:{ }^{3} \mathrm{H}$ ratio in $\mathrm{BDG}$ excreted in bile was $20-30 \%$ greater than the ${ }^{14} \mathrm{C}:{ }^{3} \mathrm{H}$ ratio in injected $\mathrm{BMG}$ and $40-50 \%$ greater than the ratio in BMG excreted in bile. When double-labeled BMG was subsequently injected with $1.7 \mu \mathrm{mol}$ unconjugated bilirubin in two of these rats, the ${ }^{14} \mathrm{C}:{ }^{3} \mathrm{H}$ ratio in BDG excreted in bile was $99.5 \%$, which was approximately equal to the ratio in injected BMG and in BMG that was excreted in bile.

Isomeric configuration of bilirubin in the conjugates excreted in bile. (a) Alkaline hydrolysis: In the infused BMG, $99.5 \%$ of ${ }^{3} \mathrm{H}$ radioactivity was in the $\mathrm{IX}_{\alpha}$ isomer. In bile from two Wistar rats after infusion of BMG, 98.9 and $99.4 \%$ of ${ }^{3} \mathrm{H}$ radioactivity was in the $\mathrm{IX}_{\alpha}$ band. (b) Alkaline methanolysis: Alkaline methanolysis of the injected bilirubin monoglucuronide preparation yielded $\sim 2 \%$ dimethylester (Table II). In two Gunn rats, $8-10 \%$ of methylesters produced by alkaline methanolysis of bilirubin conjugates excreted in bile after infusion of $\left[{ }^{3} \mathrm{H}\right]$ bilirubin monoglucuronide was bilirubin dimethylester. There was no significant difference in the isomeric composition of bilirubin monomethylesters between the injected material and that excreted in bile (Table II). After injection of labeled monoglucuronide in a Wistar rat and alkaline methanolysis of pigments excreted in bile, $30 \%$ of radioactivity in bile was found in the dimethylester. Again, there was no change in the isomeric composition of the monomethylester (Table II).

Infusion of $\left[{ }^{3} \mathrm{H}\right]$ bilirubin di- $\left[{ }^{14} \mathrm{C}\right]$ glucuronide in homozygous Gunn rats (Table III). After infusion of double-labeled BDG, $90 \%$ of ${ }^{3} \mathrm{H}$ radioactivity and $82-$ $85 \%$ of ${ }^{14} \mathrm{C}$ radioactivity were recovered in bile in 30 min. From 5 to $7 \%$ of injected ${ }^{3} \mathrm{H}$ radioactivity was in BMG. The ${ }^{14} \mathrm{C}:{ }^{3} \mathrm{H}$ ratio in BDG excreted in bile was only $10 \%$ greater than the ratio in BMG excreted in bile.

Experiments in isolated perfused homozygous Gunn rat liver (Table IV). Unconjugated bilirubin concentrations in the liver of two control Gunn rats were 51 and $48 \mathrm{nmol} / \mathrm{g}$ wet weight of liver, respectively. In two Gunn rats from the same litter, after $30 \mathrm{~min}$ perfusion with an albumin-containing perfusate, the hepatic unconjugated bilirubin concentrations were $\mathbf{1 5 . 2}$ and $14.2 \mathrm{nmol} / \mathrm{g}$ liver, respectively. After infusion of $\left[{ }^{3} \mathrm{H}\right]$ bilirubin monoglucuronide $(37-40 \mathrm{nmol}), 60-80 \%$ of radioactivity was excreted in bile in $30 \mathrm{~min}$ (Table IV). When $\left[{ }^{3} \mathrm{H}\right]$ bilirubin monoglucuronide was infused in unconjugated bilirubin-depleted liver, $20-25 \%$ of injected radioactivity was in BDG in bile. When $\left[{ }^{3} \mathrm{H}\right]$ bilirubin monoglucuronide was injected after repletion of hepatic unconjugated bilirubin by perfusion with bilirubin-containing perfusate, only $8-10 \%$ of injected radioactivity was excreted in bile as BDG.

Conversion of BDG and unconjugated bilirubin to $B M G$ in vitro. Formation of BMG was linear at 3.3 $\mathrm{nmol} / \mathrm{mg}$ per min during $6 \mathrm{~min}$ of incubation (Fig. 3).

\section{DISCUSSION}

Several methods for separation of bilirubin conjugates from bile have been reported. Onishi et al. (22) and Jansen et al. (23) used pentane sulfonic acid and tetrabutyl ammonium hydrogen sulfate, respectively, for "paired ion chromatography". Blanckaert sepa- 
TABLE I

Infusion of $\left[{ }^{3} \mathrm{H}\right]$ Bilirubin Mono $\left.-{ }^{14} \mathrm{C}\right]$ Glucuronide in Homozygous Gunn and Wistar Rats

\begin{tabular}{|c|c|c|c|c|c|c|c|c|c|c|c|c|}
\hline & \multicolumn{4}{|c|}{ Bilirubin monoglucuronide injected } & \multicolumn{4}{|c|}{ Bilirubin diglucuronide in bile } & \multicolumn{4}{|c|}{ Bilirubin monoglucuronide in bile } \\
\hline & & ${ }^{3} \mathbf{H}$ & ${ }^{14} \mathrm{C}$ & ${ }^{14} \mathrm{C} /{ }^{3} \mathrm{H}$ & & ${ }^{3} \mathbf{H}$ & ${ }^{14} \mathrm{C}$ & ${ }^{14} \mathrm{C} /{ }^{3} \mathrm{H}$ & & ${ }^{3} \mathrm{H}$ & ${ }^{14} \mathrm{C}$ & ${ }^{14} \mathrm{C} /{ }^{3} \mathrm{H}$ \\
\hline & nmol & $d p m$ & $d p m$ & & nmol & $d p m$ & $d p m$ & & nmol & $d p m$ & $d p m$ & \\
\hline \multicolumn{13}{|c|}{ Gunn rats } \\
\hline 1 & 150 & 56,005 & 8,409 & 0.15 & 23 & 8,421 & 2,526 & 0.30 & 89 & 33,562 & 5,034 & 0.15 \\
\hline 2 & 80 & 6,800 & 5,632 & 0.83 & 7 & 608 & 973 & 1.60 & 45 & 3,852 & 3,159 & 0.82 \\
\hline 3 & 40 & 5,280 & 3,018 & 0.57 & 3.4 & 444 & 493 & 1.12 & 24 & 3,151 & 1,796 & 0.57 \\
\hline \multicolumn{13}{|c|}{ Wistar rats, without bilirubin } \\
\hline 1 & 160 & 64,000 & 9,800 & 0.15 & 43 & 17,280 & 3,629 & 0.21 & 101 & 40,320 & 4,435 & 0.11 \\
\hline 2 & 40 & 21,018 & 4,623 & 0.22 & 12 & 6,165 & 1,654 & 0.27 & 23.5 & 12,328 & 2,223 & 0.18 \\
\hline 3 & 37 & 18,060 & 4,515 & 0.25 & 9 & 4,921 & 1,599 & 0.33 & 24 & 11,601 & 2,434 & 0.21 \\
\hline $4 A$ & 20 & 16,284 & 6,888 & 0.42 & 7.2 & 6,514 & 3,283 & 0.50 & 11 & 8,793 & 3,341 & 0.38 \\
\hline $5 A$ & 20 & 16,884 & 6,078 & 0.36 & 5 & 4,389 & 2,054 & 0.47 & 13 & 10,807 & 3,458 & 0.31 \\
\hline \multicolumn{13}{|c|}{ Wistar rats, after injection of $1.7 \mu \mathrm{mol}$ unconjugated bilirubin } \\
\hline 4B & 20 & 16,284 & 6,888 & 0.42 & 6 & 5,210 & 2,190 & 0.42 & 11 & 9,119 & 3,739 & 0.41 \\
\hline 5B & 20 & 16,884 & 6,078 & 0.36 & 5 & 4,137 & 1,530 & 0.37 & 13 & 10,975 & 3,951 & 0.36 \\
\hline
\end{tabular}

$\left[{ }^{3} \mathrm{H}\right]$ bilirubin mono- ${ }^{14} \mathrm{Clglucuronide}$ was biosynthesized, purified by tlc, dissolved in $1.0 \mathrm{ml}$ rat serum and injected intravenously. Bile was collected for $30 \mathrm{~min}$, pigments were separated by tlc or HPLC (see Methods) and ${ }^{3} \mathrm{H}$ and ${ }^{14} \mathrm{C}$ were quantitated. The data shown are after correction for quench and crossover of ${ }^{3} \mathrm{H}$ counts into ${ }^{14} \mathrm{C}$ channel and vice versa. The data represent individual experiments. In Wistar rats 4 and 5, the double-labeled pigment was injected once alone (A) and once after the injection of $1.7 \mu$ mol unconjugated bilirubin (B).

rated bilirubin methylesters following alkaline methanolysis of bilirubin conjugates (19). The method reported here is accurate, reproducible, highly sensitive and adaptable to radioassay. In contrast to the alkaline methanolysis method, the present method does not require replacement of the conjugating moiety, sep- arates the different sugar conjugates, and permits study of the metabolic fate of the sugar moiety.

Pure BMG and BDG standards are not available. To circumvent this problem, we biosynthesized $\left[{ }^{3} \mathrm{H}\right]$ bilirubin mono- and diglucuronide from radiochemically pure $\left[{ }^{3} \mathrm{H}\right]$ bilirubin $\mathrm{IX}_{\alpha}$. Thus, pigments sep-

TABLE II

Isomeric Configuration of Labeled Bile Pigments Determined by Alkaline Methanolysis

\begin{tabular}{|c|c|c|c|c|c|c|c|c|c|}
\hline & \multicolumn{5}{|c|}{ Injected, $n m o l(d p m)$} & \multicolumn{4}{|c|}{ Excreted in bile, $n m o l(d p m)$} \\
\hline & \multirow[b]{2}{*}{ DME } & \multicolumn{3}{|c|}{ MME } & \multirow[b]{2}{*}{ UCB } & \multirow[b]{2}{*}{ DME } & \multicolumn{3}{|c|}{ MME } \\
\hline & & $\mathbf{I I I}_{\alpha}$ & $\mathrm{IX}_{\boldsymbol{\alpha}}$ & $\mathbf{X I I I}_{\alpha}$ & & & III $_{\alpha}$ & $\mathrm{IX}_{\boldsymbol{\alpha}}$ & $\mathrm{XIII}_{\alpha}$ \\
\hline Gunn rat 1 & $\begin{array}{c}2.0 \\
(2,430)\end{array}$ & $\begin{array}{c}2.6 \\
(4,275)\end{array}$ & $\begin{array}{c}93.4 \\
(115,484)\end{array}$ & $\begin{array}{c}2.1 \\
(3,501)\end{array}$ & $\begin{array}{c}1.8 \\
(2,997)\end{array}$ & $\begin{array}{c}6.5 \\
(10,851)\end{array}$ & $\begin{array}{c}1.6 \\
(2,684)\end{array}$ & $\begin{array}{c}78.7 \\
(97,659)\end{array}$ & $\begin{array}{c}1.3 \\
(2,198)\end{array}$ \\
\hline Gunn rat 2 & $\begin{array}{c}1.8 \\
(3,726)\end{array}$ & $\begin{array}{c}3.4 \\
(7,074)\end{array}$ & $\begin{array}{c}81.1 \\
(163,179)\end{array}$ & $\begin{array}{c}2.7 \\
(5,693)\end{array}$ & $\begin{array}{c}1.5 \\
(3,768)\end{array}$ & $\begin{array}{c}7.6 \\
(15,993)\end{array}$ & $\begin{array}{c}2.0 \\
(4,230)\end{array}$ & $\begin{array}{c}58.1 \\
(121,608)\end{array}$ & $\begin{array}{c}1.7 \\
(3,474)\end{array}$ \\
\hline Wistar rat & $\begin{array}{c}1.0 \\
(2,709)\end{array}$ & $\begin{array}{c}0.5 \\
(1,382)\end{array}$ & $\begin{array}{c}49.0 \\
(132,741)\end{array}$ & $\begin{array}{c}0.5 \\
(1,301)\end{array}$ & $\begin{array}{c}0.9 \\
(2,439)\end{array}$ & $\begin{array}{c}14.2 \\
(38,468)\end{array}$ & $\begin{array}{c}0.4 \\
(1,057)\end{array}$ & $\begin{array}{c}32.4 \\
(87,771)\end{array}$ & $\begin{array}{l}0.3 \\
(840)\end{array}$ \\
\hline
\end{tabular}

See text for experimental details. The data are results of individual experiments. DME, bilirubin dimethylester; MME, bilirubin monomethylester; UCB, unconjugated bilirubin. 
TABLE III

Infusion of $\left[{ }^{3} \mathrm{H}\right]$ Bilirubin Di- $\left[{ }^{14} \mathrm{C}\right]$ Glucuronide in Homozygous Gunn Rats

\begin{tabular}{|c|c|c|c|c|c|c|c|c|c|c|c|c|}
\hline \multicolumn{5}{|c|}{ Injected bilirubin diglucuronide } & \multicolumn{8}{|c|}{ In bile } \\
\hline \multirow{2}{*}{$\begin{array}{c}\text { Gunn } \\
\text { rat }\end{array}$} & \multirow[b]{2}{*}{ nmol } & \multirow[b]{2}{*}{${ }^{3} \mathbf{H}$} & \multirow[b]{2}{*}{${ }^{14} \mathrm{C}$} & \multirow[b]{2}{*}{${ }^{14} \mathrm{C} /{ }^{3} \mathrm{H}$} & \multicolumn{4}{|c|}{ Bilirubin diglucuronide } & \multicolumn{4}{|c|}{ Bilirubin monoglucuronide } \\
\hline & & & & & nmol & ${ }^{{ }^{3}} \mathbf{H}$ & ${ }^{14} \mathrm{C}$ & ${ }^{14} \mathrm{C} /{ }^{3} \mathrm{H}$ & nmol & ${ }^{\mathbf{s}_{\mathbf{H}}}$ & ${ }^{14} \mathrm{C}$ & ${ }^{14} \mathrm{C} /{ }^{3} \mathrm{H}$ \\
\hline & & $d p m$ & $d p m$ & & & $d p m$ & $d p m$ & & & $d p m$ & $d p m$ & \\
\hline 1 & 40 & 20,090 & 4,041 & 0.20 & 33.5 & 16,815 & 3,195 & 0.19 & 2.5 & 1,265 & 228 & 0.18 \\
\hline 2 & 37 & 67,422 & 12,136 & 0.17 & 29.3 & 53,573 & 9,643 & 0.18 & 2.5 & 4,556 & 683 & 0.15 \\
\hline 3 & 38 & 52,862 & 15,330 & 0.29 & 29.0 & 40,370 & 10,900 & 0.27 & 2.9 & 3,996 & 1,039 & 0.25 \\
\hline
\end{tabular}

$\left[{ }^{3} \mathrm{H}\right]$ bilirubin di- $-{ }^{14} \mathrm{Clglucuronide}$ was biosynthesized and purified by tlc as described in Methods. The pigment was dissolved in $1 \mathrm{ml}$ rat serum and injected intravenously. Bile was collected for $30 \mathrm{~min}$, pigments were separated by HPLC, and ${ }^{3} \mathrm{H}$ and ${ }^{14} \mathrm{C}$ were quantitated. The data represent individual experiments.

arated by HPLC could be quantitated from radioactivity, and nanomoles per unit area under the chromatographic peaks would be determined.

When $\left[{ }^{3} \mathrm{H}\right]$ bilirubin mono- $\left[{ }^{14} \mathrm{C}\right]$ glucuronide was infused in homozygous Gunn rats, it was partly converted to BDG. This confirms our previous observations (8). Because Gunn rats lack UDP-glucuronate glucuronyl transferase activity, conversion of BMG cannot be due to transfer of a glucuronic acid moiety from UDP glucuronic acid. The ${ }^{14} \mathrm{C}:{ }^{3} \mathrm{H}$ ratio in BDG excreted in bile was double the ratio in injected BMG indicating that the second glucuronyl group is entirely derived by dismutation from injected labeled BMG.
When double-labeled BMG was infused in normal rats, the ${ }^{14} \mathrm{C}:{ }^{3} \mathrm{H}$ ratio in BDG in bile was greater than, but less than double, the ratio in injected BMG and in BMG excreted in bile. $\left[{ }^{3} \mathrm{H}\right]$ bilirubin produced during dismutation of injected $\left[{ }^{3} \mathrm{H}\right]$ bilirubin mono- $\left[{ }^{14} \mathrm{C}\right]$ glucuronide does not appear in bile and, in a normal rat, is probably converted to BMG and BDG. Therefore, the ${ }^{14} \mathrm{C}:{ }^{3} \mathrm{H}$ ratio in $\mathrm{BDG}$ excreted in bile is expected to be less than double the ratio in injected BMG. Partial conversion of $\left[{ }^{3} \mathrm{H}\right]$ bilirubin to BMG may also explain why the ${ }^{14} \mathrm{C}:{ }^{3} \mathrm{H}$ ratio in $\mathrm{BMG}$ excreted in bile is less than the ratio in injected BMG. Conversion of injected labeled BMG to BDG may also result from UDP glu-

TABLE IV

Bilirubin Monoglucuronide and Diglucuronide Excretion in Bile by Isolated Perfused Gunn Rat Liver after Injection of $\left[{ }^{3}\right.$ H]Bilirubin Monoglucuronide during Intrahepatic Unconjugated Bilirubin Depletion and Repletion

\begin{tabular}{|c|c|c|c|c|c|c|c|c|}
\hline \multirow[b]{3}{*}{ Experiment } & & & \multicolumn{6}{|c|}{ Excreted in bile } \\
\hline & \multicolumn{2}{|c|}{$\begin{array}{l}\text { Injected bilirubin } \\
\text { monoglucuronide }\end{array}$} & \multicolumn{3}{|c|}{ Bilirubin depletion } & \multicolumn{3}{|c|}{ Bilirubin repletion } \\
\hline & nmol & DPM & BMG & BDG & BDG & BMG & BDG & BDG \\
\hline & & & \multicolumn{2}{|c|}{ nmol } & $\begin{array}{c}\% \text { total } \\
\text { conjugates }\end{array}$ & \multicolumn{2}{|c|}{ nmol } & $\begin{array}{l}\% \text { total } \\
\text { conjugates }\end{array}$ \\
\hline 1 & 37 & 112,266 & 17.1 & 5.7 & 25 & 18.5 & 2.1 & 10.2 \\
\hline 2 & 40 & 32,010 & 15.9 & 7.5 & 32 & 15.2 & 1.3 & 7.9 \\
\hline 3 & 38 & 44,020 & 13.6 & 7.8 & 36 & 20.6 & 3.2 & 13.6 \\
\hline 4 & 40 & 119,595 & 18.2 & 9.3 & 34 & 22.7 & 3.2 & 13.1 \\
\hline 5 & 37 & 119,260 & 16.0 & 5.3 & 25 & 22.8 & 2.0 & 8.0 \\
\hline Mean \pm SD & $38.4 \pm 1.5$ & & $16.16 \pm 1.7$ & $7.1 \pm 1.6$ & $30.4 \pm 5.1$ & $20.0 \pm 3.2$ & $2.4 \pm 0.8$ & $10.6 \pm 2.7$ \\
\hline
\end{tabular}

Gunn rat liver was perfused in situ with a buffer containing $2.5 \%$ bovine serum albumin for 30 min. This procedure depleted intrahepatic unconjugated bilirubin concentration by $70 \%$. $\left[{ }^{3} \mathrm{H}\right]$ bilirubin monoglucuronide was biosynthesized and purified as described in Methods, dissolved in $5 \mathrm{ml}$ of perfusion fluid, and injected in the portal vein. Bile was collected for 30 min, pigments were separated by tlc, and quantitated from radioactivity. After this period, unconjugated bilirubin was added to the perfusate at $0.34 \mathrm{mM}$. After $30 \mathrm{~min}$ [ ${ }^{3} \mathrm{H}$ ] bilirubin monoglucuronide was injected again, bile was collected for $30 \mathrm{~min}$, and pigments were quantitated. 


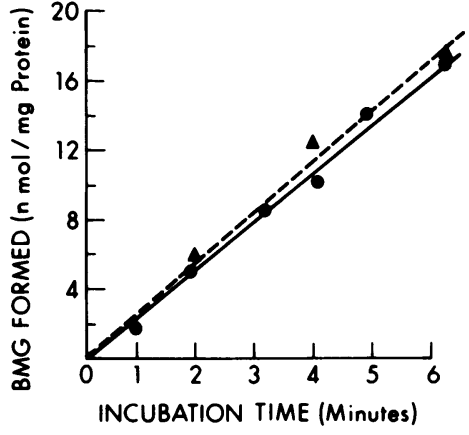

FIGURE 3 Conversion of BDG and unconjugated bilirubin to BMG. BDG was biosynthesized and purified as described in text. BDG $4 \mu \mathrm{M}$, and unconjugated $\left[{ }^{3} \mathrm{H}\right]$ bilirubin $10 \mu \mathrm{M}$ $(0.5 \mu \mathrm{Ci})$ were incubated with a rat liver plasma membrane preparation (15), $20 \mu \mathrm{g}$, in a final volume of $0.2 \mathrm{ml}$ at $\mathrm{pH}$ 6.6 in sodium phosphate buffer, $0.05 \mathrm{M}$ containing $0.25 \%$ Triton $\mathrm{X}-100$, at $37^{\circ} \mathrm{C}$. Pigments were extracted and analyzed by HPLC as described in text. BMG formation was quantitated from area under the appropriate chromatographic peak (-- ) and from incorporation of ${ }^{3} \mathrm{H}$ radioactivity $(\mathrm{O}-\mathrm{O})$.

curonate glucuronyl transferase catalyzed transfer of a glucuronyl moiety from UDP glucuronate (24).

These results initially appeared contradictory to the results of Blanckaert et al., who infused $\left[{ }^{3} \mathrm{H}\right]$ bilirubin mono- $\left[{ }^{14} \mathrm{C}\right]$ glucuronide in Wistar rats and did not find a higher ${ }^{14} \mathrm{C}:{ }^{3} \mathrm{H}$ ratio in BDG excreted in bile as compared to the ratio in injected BMG (24). However, the experimental design was different; Blanckaert et al. (24) infused double labeled BMG with an excess of unconjugated bilirubin. To evaluate the effect of unconjugated bilirubin infusion, we infused $\left[{ }^{3} \mathrm{H}\right]$ bilirubin mono- $\left[{ }^{14} \mathrm{C}\right]$ glucuronide in Wistar rats and, $1 \mathrm{~h}$ later, repeated the infusion with addition of $1.7 \mu \mathrm{mol}$ unconjugated bilirubin. When $\left[{ }^{3} \mathrm{H}\right]$ bilirubin mono$\left[{ }^{14} \mathrm{C}\right]$ glucuronide was infused alone, the ${ }^{14} \mathrm{C}:{ }^{3} \mathrm{H}$ ratio in BDG excreted in bile was greater than the ${ }^{14} \mathrm{C}:{ }^{3} \mathrm{H}$ ratio in BMG that was injected or excreted in bile. When double labeled BMG was infused with an excess of unconjugated bilirubin, the ${ }^{14} \mathrm{C}:{ }^{3} \mathrm{H}$ ratio in BDG excreted in bile was equal to the ratio in injected $\mathrm{BMG}$ and BMG excreted in bile. These results confirm the studies of Blanckaert et al. (24), and suggest that, at physiological intrahepatic bilirubin concentrations, BMG is converted to BDG largely by dismutation. At higher intrahepatic unconjugated bilirubin concentrations, dismutation is inhibited, and BDG formation continues at a lower rate, which is catalyzed by UDP glucuronate glucuronosyl transferase.

The results of experiments with isolated perfused Gunn rat liver support this hypothesis. When intrahepatic bilirubin was depleted by perfusion with an albumin-containing solution, $\sim 20 \%$ of injected BMG was excreted in bile as BDG. Repletion of the intrahepatic bilirubin concentration decreased the conversion of BMG to diglucuronide to 8-14\%. Similar conversion was observed when intact Gunn rats were injected with $\left[{ }^{3} \mathrm{H}\right]$ bilirubin mono- $\left[{ }^{14} \mathrm{C}\right]$ glucuronide. The lower percent conversion of BMG to BDG in intact Gunn rats compared to Wistar rats may be related to both UDP-glucuronosyl transferase deficiency and inhibition of enzymatic dismutation of BMG by high intrahepatocellular unconjugated bilirubin concentration.

The physiologic purpose of two enzymatic mechanisms for conversion of BMG to BDG is not clear, since BMG is readily excreted by liver (7). However, the present study indicates that both glucuronyl transferase and dismutation of BMG function in vivo to convert BMG to BDG. BMG can also be converted to BDG by nonenzymatic dipyrrolic disproportionation in vitro $(18,25)$. In this free radical reaction, symmetrical bilirubin isomers, III $_{\alpha}$ and $\mathrm{XIII}_{\alpha}$ are formed $(18,25)$. Since bilirubin in bile is almost exclusively $\mathrm{IX}_{\alpha}$, dipyrrolic scrambling is not important in BDG formation in vivo. In the present study, we searched for nonenzymatic dipyrrolic disproportionation by alkaline hydrolyis and alkaline methanolysis of bilirubin conjugates in the infusate and in the conjugates excreted in bile. Alkaline hydrolysis of the last $0.1 \mathrm{ml}$ of the infused bilirubin monoglucuronide preparation and of bilirubin conjugates excreted in Wistar rat bile after infusion of the labeled BMG indicated negligible formation of $\mathrm{III}_{\alpha}$ and $\mathrm{XIII}_{\alpha}$ isomers. In other experiments, random dipyrrolic scrambling during infusion was prevented by addition of $4 \mathrm{mM}$ ascorbate (25) in the infusate. Alkaline methanolysis of conjugated bilirubin excreted in bile after infusion of labeled BMG in two Gunn rats and one Wistar rat showed BDG formation without appreciable change in the isomeric composition of BMG. The results indicate that conversion of BMG to BDG cannot be explained by random nonenzymatic dipyrrolic disproportionation.

To study the participation of other glucuronides in the enzymatic conversion of BMG to BDG, $p$-nitrophenol glucuronide or phenolphthalein glucuronide were incubated with BMG and a rat liver plasma membrane fraction (15) in presence of a $\beta$-glucuronidase inhibitor, glucaro-1,4-lactone. Conversion of BMG to BDG was not associated with formation of unconjugated p-nitrophenol or phenolphthalein; BMG is the only known substrate for the dismutating enzyme.

The mechanism of inhibition of dismutation by high intrahepatic unconjugated bilirubin concentration is not known. Reversal of the dismutation reaction (i.e., conversion unconjugated bilirubin and BDG to BMG) is a possible mechanism. Such reversal of dismutation 
was observed in vitro and in vivo in the present study. The ${ }^{14} \mathrm{C}:{ }^{3} \mathrm{H}$ ratio in $\mathrm{BMG}$ excreted in bile following infusion of $\left[{ }^{3} \mathrm{H}\right]$ bilirubin $\mathrm{di}-\left[{ }^{14} \mathrm{C}\right]$ glucuronide was only $10 \%$ less than the ratio in injected double-labeled BDG. If conversion of BDG to BMG were due to partial hydrolysis, the expected ${ }^{14} \mathrm{C}:{ }^{3} \mathrm{H}$ ratio in BMG would be half the ratio in injected $B D G$. The results indicate that conversion of injected BDG to BMG is not predominantly due to hydrolysis, but represents reversal of the dismutation reaction. Inhibition of dismutation of BMG by high intrahepatic unconjugated bilirubin concentrations may provide an explanation for the high proportion of BMG in the bile of patients with congenital nonhemolytic unconjugated hyperbilirubinemia, such as in Gilbert's syndrome or CriglerNajjar syndrome, Type II (26).

\section{ACKNOWLEDGMENTS}

This study was supported by National Institutes of Arthritis, Metabolism, and Digestive Diseases grants AM 2019, AM 17702, and AM 23026. Dr. J. Roy Chowdhury is a recipient of a Clinical Investigator Award to the National Institutes of Arthritis, Metabolism, and Digestive Diseases.

\section{REFERENCES}

1. Fevery, J., B. Van Damme, R. Michiels, J. de Groote, and $K$. P. M. Heirwegh. 1972. Bilirubin conjugates in bile of man and rat in the normal state and in liver disease. J. Clin. Invest. 51: 2482-2492.

2. Billing, B. H., P. G. Cole, and G. H. Lathe. 1957. The excretion of bilirubin as a diglucuronide giving direct Van den Bergh reaction. Biochem. J. 65: 774-784.

3. Gordon, E. R., M. Dadoun, C. A. Goresky, T. H. Chan, and A. S. Perlin. 1974. The isolation of an azobilirubin $\alpha$-D monoglucoside from dog gall bladder or bile. Biochem. J. 143: 97-105.

4. Fevery, J., P. Leroy, M. Van de Vijver, and K. P. M. Heirwegh. 1972. Structures of bilirubin conjugates synthesized in vitro fom bilirubin and uridine diphosphate glucuronic acid, uridine diphosphate glucose or uridine diphosphate xylose by preparations from rat liver. Biochem. J. 129: 635-644.

5. Heirwegh, K. P. M., M. van de Vijver, and J. Fevery. 1972. Assay of uridine diphosphate glucuronyl transferase from rat liver. Biochem. J. 129: 605-618.

6. Jansen, P. L. M., J. Roy Chowdhury, E. B. Fischberg, and I. M. Arias. 1977. Enzymatic conversion of bilirubin monoglucuronide to diglucuronide by rat liver plasma membranes. J. Biol. Chem. 252: 2710-2716.

7. Roy Chowdhury, J., P. L. M. Jansen, E. B. Fischberg, A. Daniller, and I. M. Arias. 1978. Hepatic conversion of bilirubin monoglucuronide to bilirubin diglucuronide in uridine diphosphate glucuronyl transferase deficient man and rat by bilirubin glucuronoside glucuronosyl transferase. J. Clin. Invest. 21: 191-196.

8. Roy Chowdhury, J., N. Roy Chowdhury, M. Bhargava, and I. M. Arias. 1979. Purification and partial characterization of rat liver bilirubin glucuronoside glucuronosyl transferase. J. Biol. Chem. 254: 8336-8339.

9. Jansen, P. L. M., 1974. The enzyme catalyzed formation of bilirubin diglucuronide by a solubilized preparation from cat liver microsomes. Biochim. Biophys. Acta. 338: 170-182.

10. Blanckaert, N., J. Gollan, and R. Schmid. 1979. Bilirubin diglucuronide synthesis by a UDP-glucuronic acid-dependent enzyme system in rat liver microsomes. Proc. Natl. Acad. Sci. U.S.A. 76(4): 2037-2041.

11. Howe, R. B., P. D. Berk, J. R. Bloomer, and N. I. Berlin. 1970. Preparation and properties of specifically labeled radiochemically stable ${ }^{3} \mathrm{H}$-bilirubin. J. Lab. Clin. Med. 75: 499-502.

12. Barrett, P. V. D., J. X. Mullins, and N. I. Berlin. 1966. Studies on the biosynthetic production of bilirubin ${ }^{14} \mathrm{C}$. An improved method utilizng $\delta$-aminolevulinic acid-4$\mathrm{C}^{14}$ in dogs. J. Lab. Clin. Med. 68: 905-912.

13. McDonagh, A. F., and F. Assisi. 1971. Commercial bilirubin: a trinity of isomers. FEBS (Fed. Eur. Biochem. Soc.) Lett. 18: 315-317.

14. Heirwegh, K. P. M., J. Fevery, R. Michiels, G. P. Van Hees, and F. Compernolle. 1975. Separation by thin layer chromatography and structure elucidation of bilirubin conjugates isolated from dog bile. Biochem. J. 145: 185-199.

15. Touster, O., N. H. Aronson, J. T. Dulaney, and H. Hendrickson 1970. Isolation of rat liver plasma membranes. Use of nucleotide phosphatase and phosphodiesterase-I as marker enzymes. J. Cell Biol. 47: 604-618.

16. Blanckaert, N., F. Compernolle, P. Leroy, R. V. Houtte, J. Fevery, and K. P. M. Heirwegh. 1978. The fate of bilirubin-IX glucuronide in cholestasis and during storage in vitro. Biochem. J. 171: 203-214.

17. Heirwegh, K. P. M., G. P. Van Hees, P. Leroy, F. P. Van Roy, and F. H. Jansen. 1970. Heterogeneity of bile pigment conjugates by chromatography of their ethyl anthranilate azopigments. Biochem. J. 120: 877-890.

18. Jansen, P. L. M. 1973. The isomerization of bilirubin monoglucuronide. Clin. Chim. Acta. 49: 233-240.

19. Blanckaert, N. 1980. Analysis of bilirubin mono- and diconjugates. Determination of their relative amounts in biological fluids. Biochem. J. 185: 115-128.

20. McDonagh, A. F., and F. Assisi. 1972. Direct evidence for the acid-catalyzed isomeric scrambling of bilirubin IX. J. C. S. Chem. Comm. 1/1972: 117-119.

21. Van Roy, F. P., J. A. T. P. Meuwissen, F. de Meuter, and K. P. M. Heirwegh. 1971. Determination of bilirubin in liver homogenates and serum with diazotized p-iodoaniline. Clin. Chim. Acta. 31: 109-118.

22. Onishi, S., S. Iloh, N. Kawade, K. Isobe, and S. Sugiyama. 1980. An accurate and sensitive analysis by high pressure liquid chromatography of conjugated and unconjugated bilirubin IX and in various biological fluids. Biochem. J. 185: 281-284.

23. Jansen, P. L. M., and A. Tangerman. 1980. Separation and characterization of bilirubin conjugates by high performance liquid chromatography. J. Chromatogr. 182: 100-104.

24. Blanckaert, N., J. Gollan, and R. Schmid. 1980. Mechanism of bilirubin diglucuronide formation in intact rats. J. Clin. Invest. 65: 1332-1342.

25. Sieg, A., and K. P. M. Heirwegh. 1981. Evidence against enzymatic conversion in vitro of bilirubinmono- to bilirubindiglucuronide in preparations from Gunn rat liver. Gastroenterology. 80: 1349. (Abstr.)

26. Fevery, J., N. Blanckaert, K. P. M. Heirwegh, A. M. Preaux, and P. Berthelot. 1977. Unconjugated bilirubin and an increased proportion of bilirubin monoconjugates in the bile of patients with Gilbert syndrome and CriglerNajjar disease. J. Clin. Invest. 60: 970-979. 